\title{
Avaliação da organização estrutural das vigilâncias sanitárias municipais de uma Região de Saúde de Pernambuco
}

\author{
I ${ }^{1}$ Ewerton Handerson Figueiredo de Medeiros, ${ }^{2}$ Michael Ferreira Machado, \\ 3 João Mário Pessoa Júnior I
}

Resumo: $\mathrm{O}$ artigo trata de pesquisa descritiva e qualitativa que objetivou avaliar a estrutura organizacional das vigilâncias sanitárias de 11 municípios que estão inseridos na décima região de saúde do Estado de Pernambuco, Brasil. Constituíramse como os principais interlocutores do estudo, 11 coordenadores de saúde. Utilizou-se a técnica de entrevista baseada em roteiro semiestruturado. Os dados analisados foram obtidos através da técnica "análise de enunciação", em que a comunicação foi interpretada como um processo, respeitando a lógica do discurso. Os resultados apontaram fragilidade dos serviços municipais de vigilância sanitária diante do processo de descentralização de ações, não conseguindo responder, em sua totalidade, às demandas oriundas do território. Entre os problemas, destacam-se a insuficiência de recursos humanos; inexistência de uma política de educação permanente; dificuldades nas relações interpessoais entre gestores; insuficiência de recursos financeiros; a falta de espaço físico adequado, veículos próprios, instrumentos tecnológicos; dificuldades em desenvolverem açôes intersetoriais e no planejamento de instrumentos de gestão. Reconhecese a necessidade de maior engajamento entre gestores e trabalhadores na busca pela reestruturação de suas ações e práticas cotidianas, com vistas ao funcionamento de forma descentralizada, prezando pela eficiência de seus serviços.

> Palavras-chave: vigilância sanitária; descentralização; gestão em saúde; estrutura dos serviços.

\author{
1 Escola de Governo em Saúde \\ Pública de Pernambuco. Recife- \\ PE, Brasil (ewertonfigueiredo7@ \\ gmail.com) \\ ${ }^{2}$ Faculdade de Medicina, \\ Universidade Federal de \\ Alagoas. Arapiraca-AL, Brasil \\ (michael.ufal@gmail.com). \\ ${ }^{3}$ Centro de Ciências \\ Biológicas e da Saúde, \\ Universidade Federal Rural do \\ Semiárido. Mossoró-RJ, Brasil \\ (joaomariopessoa@gmail.com).
}

Recebido em: 03/10/2016 Aprovado em: 30/05/2017 
No Brasil, a Vigilância Sanitária (Visa) se tornou uma importante área do Sistema Único de Saúde (SUS), reconhecida pelo conjunto de açôes no âmbito sanitário que propõe regular os serviços de saúde, contendo atividades relacionadas à produção de bens e serviços de interesse à saúde, estando esses ambientes inseridos nas redes pública ou privada. Desse modo, a Visa se situa num espaço de intervenção em relação ao meio de produção e consumo, onde o Estado atua no mercado e com o apoio da sociedade (COSTA, 2009).

A Lei 8.080/90, conhecida como Lei Orgânica da Saúde (LOS), em sua regulamentação, estabelece a Visa como ação específica do setor saúde, e entre suas diretrizes, destaca-se a descentralização das ações para estados e municípios, regulamentada posteriormente pelas Normas Operacionais Básicas (NOBs) e as de Assistência à Saúde (NOAS). A Visa, além de fazer parte do SUS, também integra o Sistema Nacional de Vigilância Sanitária (SNVS), que objetiva "eliminar, diminuir ou prevenir riscos à saúde e intervir nos problemas sanitários decorrentes do meio ambiente, da produção e circulação de bens e da prestação de serviços de saúde" (BRASIL, 1990). Reconhece-se que para o SNVS funcionar de forma efetiva, fazem-se necessárias maiores articulaçōes entre os profissionais da Visa e a estruturação dos serviços perante as três esferas de governo.

Nesse contexto, o processo de descentralização das ações de Visa instituído mediante a LOS, reafirmado nas publicaçôes das normas reguladoras do SUS, nos Pactos de Saúde, na criação da Agência Nacional de Vigilância Sanitária (Anvisa), assim como na normatização do SNVS, tem levantado questionamentos de como este vem sendo desenvolvido, considerando as condições atuais dos trabalhos da Visa nos contextos locais. Contudo, observa-se entre os estados e municípios da federação entraves, como recursos humanos insuficientes e mal capacitados, inadequação dos espaços físicos de trabalho, deficiência de equipamentos, de veículos e transportes, baixos índices de informatização atrelados à insuficiência dos sistemas de informação, falta de recursos financeiros para a realização de fiscalizaçôes e uma organização administrativa deficiente com códigos sanitários inexistentes ou, em muitos casos, desatualizados (MELO, 2014).

Com vistas ao fortalecimento da diretriz de descentralização das ações e serviços no âmbito da Visa, o Estado de Pernambuco expandiu nos últimos anos a Visa 
entre as 12 Gerências Regionais de Saúde (GERES) - unidades administrativas da Secretaria Estadual de Saúde (SES), que oferecem apoio aos 184 municípios pernambucanos, incluindo a ilha de Fernando de Noronha. Sabe-se que junto a esse processo, existem dificuldades relacionadas à estruturação dos serviços e acúmulo da capacidade gestora dos órgãos municipais da Visa. A própria complexidade inerente ao escopo de ações da Visa remete à compreensão de que a estrutura e organização desses órgãos enfrentam rotineiramente problemas de difícil resolução.

Soma-se ainda o fato de que muitos fatores ocasionam problemas estruturais com reflexos diretos na qualidade dos serviços prestados por estes órgãos à sociedade. Surge, portanto, a necessidade de ampliar o debate sobre a conjuntura organizacional e estrutural desses ambientes de trabalho, bem como dos profissionais ali inseridos.

Assim, a avaliação dos serviços de saúde tem se mostrado como ferramenta importante na produção de informações, as quais são capazes de propor adequações nos usos de tecnologias e tipos de gestão a ser escolhidas, direcionando os olhares para os efeitos e custos associados ao processo. Um serviço descentralizado deve possibilitar um equilíbrio entre obrigações, possibilidades e poderes, tanto do nível central como do local, o que direcionará a sociedade a usufruir o direito de garantia de acesso (SOUZA; STEIN, 2008).

$\mathrm{O}$ artigo é resultante do trabalho de conclusão de curso do Programa de Residência Multiprofissional em Saúde Coletiva, com ênfase em Gestão de Redes de Saúde, da Secretaria Estadual de Saúde de Pernambuco (PRMSC-Gestão). O PRMSC-Gestão atua exclusivamente no interior do Estado de Pernambuco, o que permite ofertar de forma descentralizada e regionalizada essa modalidade de especialização no serviço.

Dessa forma, objetivou avaliar a estrutura organizacional das vigilâncias sanitárias municipais que compõem a décima região de saúde do Estado de Pernambuco, Brasil. Nesse sentido, a escolha do local do estudo se deu pelo processo de interiorização e consolidação das VISAS em Pernambuco, bem como pela inserção dos autores nos processos de planejamento e gestão do SUS, nos municípios que compõem essa região de saúde, através do cenário de prática do programa de residência. 


\section{Percurso metodológico}

O estudo desenvolvido possui um desenho descritivo e qualitativo, foi realizado junto às vigilâncias sanitárias dos municípios inseridos na décima região de saúde do Estado de Pernambuco, nordeste do Brasil.

A X Região de Saúde está localizada no Alto Sertão do Pajeú, com área territorial de 4.308,55 $\mathrm{Km}^{2}$, com sede no município de Afogados da IngazeiraPE, sendo composta por 12 municípios, a saber: Afogados da Ingazeira, Brejinho, Carnaíba, Iguaraci, Ingazeira, Itapetim, Quixaba, Santa Terezinha, São José do Egito, Solidão, Tabira e Tuparetama, sendo este último o mais distante de sua sede. Desses munícipios, apenas Ingazeira não faz divisa territorial com o estado vizinho, Paraíba, fato que reflete o grande fluxo de mercadorias e pessoas entre os dois estados.

\section{Figura 1. Mapa de Saúde da X GERES, Pernambuco, 2013}

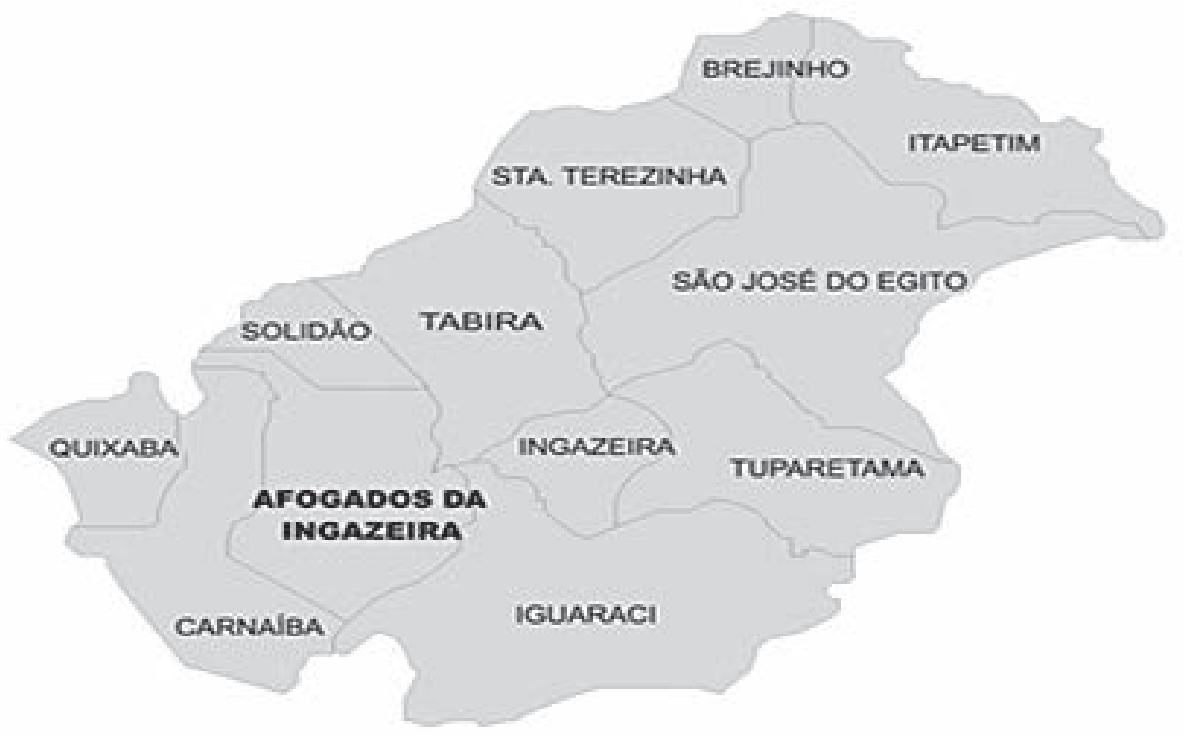

Fonte: X GERES Pernambuco.

Entre os 12 municípios que compõem a X Região de Saúde, 91,7\% possui grande extensão territorial, concentrando uma significativa parte da população $(34,4 \%)$ em áreas rurais sem acesso a água tratada. Tal fato contribui para a 
presença constante de algumas doenças de veiculação hídrica ou relacionadas à questão de higiene.

A região está localizada no semiárido nordestino, apresentando um clima quente do tipo tropical semiárido, com média de temperatura anual na faixa de 26 ${ }^{\circ} \mathrm{C}$ e preciptação média anual de $591,9 \mathrm{~mm}$, com período chuvoso entre os meses de janeiro e maio. A economia é fortemente movimentada pela agropecuária, seguida do comércio. A agricultura predominante é a de subsistência, cultivada por agricultores familiares, famílias assentadas pela reforma agrária e grupos que obsecram o acesso à terra, incluindo quilombolas (VERSYPLE et al., 2015).

Buscou-se incluir o maior número de sujeitos da pesquisa, tendo como critérios: profissionais que estavam à frente da coordenação da Visa; com tempo médio de seis meses de exercício e aceitarem participar do estudo; e excluídos aqueles que estavam afastados de seus cargos por motivos compreendidos por lei (férias, licenças médicas, entre outros). Participaram da pesquisa 11 coordenadores que estavam à frente da gestão do órgão no período de coleta de dados realizado através de entrevistas, tendo apenas uma recusa, alegando questões de ordem pessoal. Optou-se neste estudo por utilizar o termo "coordenador" ao se referir, numa escala hierárquica, ao profissional responsável pela atividade administrativa de organização e coordenação do trabalho da Visa em âmbito local.

A coleta de dados aconteceu no período entre os meses de janeiro e fevereiro de 2016, quando todos os entrevistados foram previamente consultados para agendamento de datas e horários. Os encontros com os gestores ocorreram em seus respectivos ambientes de trabalho, a fim de proporcionar maior comodidade aos participantes. As entrevistas seguiram um roteiro semiestruturado, previamente elaborado.

No processo de análise, utilizou-se a de enunciação, em que a comunicação foi interpretada como um processo, respeitando a lógica e a organização do discurso, estudando as figuras de retórica e as estruturas que estão inseridas, como os jogos de palavras, lapsos e silêncios produzidos durante a fala (MINAYO et al., 2013). Os discursos foram gravados em áudio e, em seguida, transcritos para a análise dos dados. Durante o processamento dos dados, cada órgão municipal foi considerado uma unidade de contexto e, posteriormente, seus dados foram transcritos como unidades de registro. 
Os temas foram sendo agrupados em torno dessas unidades e depois classificados de acordo com sua relevância, tendo-se o cuidado de agrupar temas comuns relacionados aos diferentes municípios, considerando suas características históricas e socioeconômicas. Ao final, os dados em formato de áudio foram excluídos do gravador digital, mantendo, assim, o compromisso exposto no Termo de Consentimento Livre e Esclarecido (TCLE), que foram previamente assinados pelos entrevistados.

A pesquisa foi encaminhada e aprovada pelo Comitê de Ética em Pesquisa da Universidade de Pernambuco, com CAAE no 50412815.7.0000.5207, seguindo os preceitos que regem a Resolução 466/2012 do Conselho Nacional de Pesquisa. No sentido de preservar o anonimato dos entrevistados, estes foram identificados por códigos (E1, E2...) durante o texto.

\section{Resultados e Discussão}

Os resultados foram estruturados em quatro unidades de análise, a saber: "Caracterização das equipes de profissionais"; "Gestão do trabalho na Visa"; "Estrutura organizacional" e "Processos operacionais e o cotidiano das ações no âmbito da Visa".

\section{Caracterização das equipes de profissionais}

Em relação ao perfil dos coordenadores das Visas, a maioria é do sexo masculino (63,4\%), com faixa etária de 45 anos e com tempo de atuação na Visa de 10,8 anos e 7,1 anos na função de coordenação.

Observa-se que as mulheres ainda não assumem funções de coordenação na mesma proporção que homens, reforçando que as desigualdades de gênero ainda são perceptíveis nas relações de trabalho existentes no Brasil, realidade que confronta o princípio constitucional da igualdade de gênero e de direitos. Porém, esses fatores negativos vêm sendo combatidos com ações afirmativas idealizadas através dos debates promovidos por grupos ligados à política de igualdade de gênero (SANTOS; CANCIANI, 2016). As equipes municipais de Visa possuem, em média, 3,3 profissionais por equipe, com os de nível médio representando $2 / 3$ da força de trabalho. Aponta-se que 30 profissionais possuem dedicação exclusiva aos órgãos, numa média de 2,7 por equipe. Notou-se também que dos 37 profissionais do total da amostra, 59,4\% possuíam vínculo estatutário. 
A quantidade de profissionais que atuam nas VISAs municipais não supre a demanda de atividades desenvolvidas pelo órgão, o que, em muitas situações, ocasiona sobrecarga de trabalho aos trabalhadores que estão em serviço. Em muitos casos, a equipe mínima não é respeitada, o que se une a outros problemas, como o de profissionais que são transferidos para outros setores da Secretaria Municipal de Saúde (SMS), além do fato de alguns gestores municipais terem desonerados agentes sanitários contratados sobre alegação de crise financeira.

Não temos nem uma equipe mínima como manda a lei e as atividades da Visa foram sendo descentralizadas para os municípios e hoje temos dificuldades de dar a cobertura a todo o município, assim não podemos garantir que tudo estará dentro dos padrões (E1).

Na maioria dos municípios, percebeu-se que os órgãos não trabalhavam em horário integral, com déficit de profissionais, o problema era intensificado em função da demanda excessiva de atividades a ser realizadas. Soma-se a isso o fato de alguns profissionais possuírem mais de um vínculo de trabalho e terem suas cargas horárias flexibilizadas pelos gestores municipais, fato relatado como um problema para o órgão, pois alguns casos se deram sem que houvesse diálogo com os coordenadores da Visa.

[...] Temos dificuldades em cumprir metas, pois além de pouquíssimos funcionários, trabalhamos em horário corrido de $6 \mathrm{~h} /$ diária e os diversos deveres, principalmente na área de alimentação de sistemas nos prendem bastante no órgão (E2).

[...] Em nossa equipe tem profissional que vem trabalhar quando pode, pois possui outros vínculos e tenta dar conta de tudo sem condiçōes suficientes para isso... mas nesse caso o coordenador não pode interferir, pois foi algo combinado com os gestores que estão acima de mim hierarquicamente (E3).

A política de recursos humanos na Visa tem sido posta como o ponto crítico da área, pois a diversificação da formação de seus profissionais, a variabilidade de vínculos de trabalho e a carga horária influenciam diretamente nas relações desses com as instituições. Buscar meios que possibilitem a implantação ou estruturação dos planos de cargos, carreiras e salários apresenta-se como uma ferramenta eficaz na resolução da alta rotatividade dos trabalhadores (MELO, 2014).

Quanto à formação educacional, a maioria possui ensino médio completo, e entre os de nível superior, apenas dois possuem pós-graduação na área de saúde coletiva. De acordo com os depoimentos, pode-se constatar que boa parte dos profissionais não passou por cursos básicos em Visa, e quanto a capacitações, 
as equipes só participam quando os entes federativos superiores ao município as realizam. Além disso, nem todos os profissionais participam de eventos de formação complementar, por diversos motivos, que vão desde a falta de interesse próprio até o número insuficiente de vagas.

\footnotetext{
Dependemos dos outros entes federativos para participarmos de capacitaçôes e nos últimos anos tem diminuído a frequência que elas vêm sendo disponibilizadas... talvez seja o atual momento de crise que vivenciamos e que tem afetado isso também... (E8).

Temos um agente na equipe que não gosta de participar de nenhuma capacitação, pois ele não consegue compreender nada que esteja ligada a tecnologia devido à idade já avançada, ele fica somente com o trabalho braçal e eu e o outro agente que faz os outros serviços (E7).
}

Garibotti et al. (2006) constataram que a maioria dos profissionais não passaram por formação específica para atuar na Visa. O ofício desenvolvido nos órgãos foi assimilado com a rotina prática, vivenciada dentro dos serviços e com a colaboração dos que já desempenhavam funções na área. A inexistência da implantação de uma política de educação permanente em Visa por parte das gestôes municipais, como também, em alguns casos, a existência de impedimentos na busca pessoal por uma melhor qualificação contribuem para que se observe uma quantidade significativa de profissionais desatualizados nas funçôes que desempenham.

\section{Gestão do trabalho na Visa}

O acúmulo de coordenações tem sido um problema na rotina da gestão do trabalho na Visa, pois impede dedicação exclusiva ao órgão. Em algumas situações, profissionais assumiram a função de coordenador da Visa sem possuírem experiência na área de saúde, o que ocasionou dificuldades iniciais, principalmente conceituais e burocráticas.

De acordo com os depoimentos, a rotatividade de secretários de saúde resulta em dificuldades no gerenciamento de projetos desenvolvidos pelos órgãos, acarretando modificações no plano de ações e, em muitos casos, a interrupção de projetos ainda em curso. A falta de diálogo entre coordenadores e secretários se apresenta como importante desafio na gestão das Visas municipais, visto que, em várias situações, o poder de compreensão se demonstra frágil nas relações pessoais, como se pode observar no depoimento a seguir: 
A falta de compreensão no diálogo com os gestores maiores também é empecilho para

gerir o órgão, pois eles sempre estão abertos a ouvir, mas demonstram pouco interesse em compreender nossa fala, reinvindicações... eles só prestam atenção as nossas falas quando é um caso que está gerando uma grande repercussão na sociedade... (E8).

A compreensão dos coordenadores acerca da Visa municipal enquanto órgão autônomo é bastante fragilizada, reforçando a percepção de um setor totalmente subordinado aos secretários e aos gestores municipais. Além disso, tem-se a falta de entendimento da população sobre as dificuldades reais vivenciadas pelos órgãos municipais, que se expressa nos atos de busca pela resolução de problemas através do imediatismo, momento em que o poder de atuação dos coordenadores passa a ser questionado quando problemas não são resolvidos em um curto espaço de tempo.

Quando se tem um órgão com grandes problemas estruturais, falar em cumprimentos de metas é um assunto delicado, pois nós vivemos pressionados por elas, mas impossibilitados de cumprir muitas delas... (E3).

As metas estão aí para serem cumpridas, mas cadê que os problemas de falta de estrutura são resolvidos antes das cobranças?... Como diz aquele ditado: "falar é fácil, difícil é arregaçar as mangas e fazer”... (E5).

A insuficiência de recursos financeiros lista, entre as dificuldades no processo de gerenciamento das ações, o que foi enfatizado pelos coordenadores dos órgãos municipais, de modo que os recursos destinados aos órgãos através de repasses de outros entes federativos não coadunam com a real necessidade financeira da Visa, e isso atrapalha o prosseguimento de trabalhos desenvolvidos.

O recurso da Visa é tão pouco que não compra nem sonhos básicos. É uma dura realidade. Não sei como as instâncias superiores sentem-se confortáveis em só cobrar dos municípios sabendo que sempre nos esbarramos com a falta de recursos financeiros. Vivemos tentando equilibrar todos os serviços para que a população não se sinta desassistida, mas confesso, é muito difícil... (E8).

No ano de 2000, a Anvisa instituiu o Termo de Ajuste e Metas de Vigilância Sanitária, o qual subsidiou o processo de descentralização de recursos financeiros por meio de compromissos previamente firmados entre a agência e os gestores municipais. Apesar da escassez desses recursos, os municípios que aderiram ao termo tinham em mãos uma maior flexibilidade para sua aplicação. A adesão era firmada após os municípios demonstrarem capacidade técnica e gerencial para o cumprimento de metas (FERRARO et al., 2009). 
Em muitos municípios, os recursos da Visa são complementados pelos da SMS, fato argumentado pelo discurso de que o montante que totaliza os recursos próprios não arca com todo o custeio do órgão. A centralidade dos recursos financeiros também foi mencionada, limitando, dessa forma, o acesso dos coordenadores às informações sobre os recursos disponíveis. Souza e Stein (2008) apontam que o desconhecimento dos recursos financeiros destinados à Visa, por parte da maioria dos seus coordenadores, reflete nas dificuldades gerenciais e na incapacidade de consolidação das atividades descentralizadas para o órgão municipal. Com isso, os serviços ficam sem condições mínimas para o desenvolvimento de açôes integrais, resultando, entre outros, na dificuldade de aplicação de recursos e gestão ineficiente devido à falta de um projeto político que busque a efetividade das ações descentralizadas da Visa.

Quanto à satisfação pessoal sobre o serviço prestado à frente da coordenação dos órgãos de Visas municipais, os gestores demonstraram, de forma unânime, ser gratos pelo trabalho que vêm produzindo, mas relataram problemas que poderiam ser superados para melhorar os níveis de satisfação no ofício. Em muitos ambientes, a motivação não é um sentimento estimulado pela gestão, apesar de haver, em muitos casos, motivação pessoal pelo trabalho desenvolvido na área (LEAL; TEIXEIRA, 2009).

\section{A estrutura organizacional da Visa}

$\mathrm{Na}$ visão dos coordenadores da maioria dos órgãos, o espaço físico destinado à Visa ainda está distante do ideal, pois falta um olhar mais sensível por parte dos gestores das três esferas de governo, que preze pelo conforto e bem-estar tanto dos profissionais como da população que procura os serviços nos órgãos da Visas municipais.

Em alguns municípios, pode-se perceber que a Visa divide o seu espaço físico com outros setores ligados à SMS, como observado no depoimento a seguir:

O nosso espaço físico deixa muito a desejar, pois são três setores da secretaria dividindo o mesmo ambiente. Você imagina como a população se sente constrangida ao chegar até a gente para denunciar irregularidades que estão acontecendo no município e perceber que a sala está lotada de funcionários de diversos setores. Eu queria uma sala só nossa, mas acho difícil a gestão nos conceder... (E7).

A inexistência de ambientes físicos para procedimentos específicos da área, como sala de vacina e de procedimentos veterinários, e também de sala 
de armazenamento de materiais recolhidos durante as fiscalizações tornou-se

uma preocupação constante dos agentes sanitários, já que dificulta os processos operacionais dos órgãos.

Diante de tantos problemas, foi relatada uma experiência exitosa de um município após reestruturação do espaço físico da Visa municipal:

Quando mudamos para o centro da cidade, percebemos um aumento significativo do numero de denúncias. As pessoas perderam mais o medo de denunciar, pois o ambiente proporciona o anonimato com salas separadas distante da SMS. Antes a Visa dividia a mesma sala com o setor da epidemiologia e eu percebia que as pessoas se sentiam inibidas (E1).

A dinamicidade da Visa exige um espaço físico capaz de suprir as demandas operacionais dos órgãos. Com isso, faz-se necessário que aja uma exigência, principalmente dos trabalhadores, para que o ambiente de trabalho garanta uma privacidade no atendimento aos usuários. Também é importante reconhecer que as atividades desenvolvidas nos órgãos possuam características humanizadas e que prezem pela qualidade dos serviços prestados à sociedade (FERRARO et al., 2009) A limitação do espaço físico também foi citada, em outros estudos, por Leal e Teixeira (2009) e Maragon et al. (2009, 2010).

A falta de veículo próprio nos órgãos das Visas municipais é um dos problemas estruturais que mais se destacam, pois interfere diretamente na dinâmica do funcionamento do serviço, o que, em muitas situações, promove a perda de resolubilidade da Visa. Para muitos órgãos, a única saída é a solicitação de veículos às SMS, e em casos que elas não disponham no momento necessitado, pedir as outras instituições dos municípios. A prática do uso de veículos através de rodízios por parte das diversas vigilâncias também é comum, sendo organizado por cronogramas, o que engessa as atividades da Visa e causa inflexibilidade na sua capacidade de atender demandas junto à população num menor espaço de tempo.

É uma dificuldade constante, pois em casos de denuncia, a VISA tem dificuldade de chegar a tempo... (E9).

Acho que toda Visa que não possui um veículo próprio sente dificuldade em cumprir metas, pois é algo que sai de sua governança e passa a depender mais de terceiros que de você próprio. Eu simplesmente fico 'sem chão' quando tinha que explicar a população que determinada ação não poderia ser realizada por falta de transporte... (E6).

Entre os municípios em que a Visa possui transporte próprio, a dinâmica do serviço fluía melhor e o órgão estava mais próximo da população. Maragon 
et al. (2010) e Cohen (2009) coadunam em suas conclusões ao afirmarem que a falta de transporte não só causa comprometimento da fiscalização sanitária, como dificulta ainda mais o arcabouço burocrático da área, ao impedir que a sociedade tenha acesso aos serviços prestados pela Visa em um menor espaço de tempo possível.

O aparato tecnológico está atrelado ao meio de trabalho da Visa, porém, em alguns órgãos, as dificuldades se dão pela falta de manutenção de equipamentos eletrônicos e aquisição de novos, que tenham configuração compatível com a necessidade do trabalho desenvolvido pelos profissionais.

A falta de tecnologia suficiente para o trabalho no órgão atrapalha muito o serviço, pois temos computadores desatualizados e que não suportam determinados sistemas e também faltam alguns equipamentos para agilizar nosso trabalho. Muitas vezes a gente leva trabalho para casa, para fazer no computador pessoal, pois os daqui não adianta tentar que vai ser trabalho perdido... (E4).

Acho que não dá para pensar mais em uma Visa moderna e dinâmica sem tecnologias suficientes pra isso. Nós trabalhamos em cima de dados todos os dias, mas nos esbarramos com dificuldades que já poderiam ter sido sanadas... (E8).

O amplo e variado campo onde as atividades da Visa estão inseridas requer um olhar integral, principalmente na prevenção de riscos, por parte dos profissionais que atuam na área. E isso faz com que os órgãos necessitem cada vez mais de tecnologias que se complementem ao serviço, trazendo eficiência na organização do trabalho (SOUZA; COSTA, 2010). Na maioria das Visas municipais, os profissionais convivem rotineiramente com a falta ou insuficiência de equipamentos e insumos adequados para a realização das atividades estabelecidas no plano de ações anual. A inexistência de manutenção contínua também faz com que os equipamentos no decorrer do tempo sofram deterioração, o que interfere diretamente no desenvolvimento das ações realizadas pelos órgãos. Muitos dos coordenadores relataram que a internet no passado foi um grande problema para o órgão, porém, agora obtiveram melhorias de sinal.

Quando chega o dia de realizar alguma atividade e está faltando algum equipamento ou material que é necessário, nós tentamos ao máximo improvisar para que a ação não deixe de acontecer... (E5).

Nós tínhamos uma grande dificuldade quanto ao sinal de internet, o que fez em muitos casos a alimentação de sistemas ficar atrasada, porém esse problema já foi superado e hoje já contamos com um sinal melhor (E10). 
Alguns coordenadores relataram que tentam se prevenir solicitando uma quantidade maior de materiais necessários para o dia a dia da Visa numa forma de garantir que nenhuma atividade previamente programada seja cancelada. A fragilidade dos ambientes de trabalho é exposta através do uso de critérios que demonstra a precariedade e escassez de insumos e equipamentos utilizados nas ações rotineiras das Visas municipais (FERRARO et al., 2009).

\section{Processos operacionais e o cotidiano das ações no âmbito da Visa}

Os serviços municipais, por unanimidade, apresentaram ações de enfoque preventivo, que vêm sendo realizadas no decorrer dos últimos anos. Várias técnicas de convivência são utilizadas para aproximar o serviço da Visa à comunidade, entre elas: rodas de conversas, palestras, visitas rotineiras a instituiçôes públicas e privadas, uso de meios de comunicações (carro de som, rádio, internet, entre outros). O foco de suas ações voltado para a prevenção remete ao sentido de precaução e cuidado, substituindo o conceito da Visa de apenas fiscalizar, controlar e punir (COSTA et al., 2008).

$\mathrm{Na}$ maioria dos órgãos estudados nesta pesquisa, parcerias com instituições e com outros profissionais vêm surtindo um efeito considerado bastante positivo. Em destaque, pode-se citar o elo entre agentes sanitários e Agentes Comunitários de Saúde (ACS), os quais, por estarem mais próximos da comunidade, fazem com que a população conheça os serviços da Visa e a busque quando necessário, como, também, contribua para o planejamento do serviço, tornando a gestão mais participativa. Entretanto, observou-se a existência de dificuldades locais para que o trabalho da Visa seja desenvolvido de forma intersetorial, fragilidades gerenciais e um baixo poder de diálogo podem estar interferindo nesse contexto.

Não consigo imaginar o trabalho da Visa progredindo sem a busca de parcerias. Você veja que mesmo trabalhando com elas as dificuldades são inúmeras, imagina sem... (E1).

Muitas das ações de prevenção, principalmente de doenças que geraram surtos, ficam a cargo da epidemiologia e nós não nos metemos muito, só quando somos chamados (E2).

A busca pela cooperação técnica entre as instituições deve ser uma política permanente em todas as gestôes, estando as propostas de parcerias solidificadas nesse meio, o que mostrará a capacidade de articulação e gerenciamento dos 
gestores locais (LEAL; TEIXEIRA, 2009). O instrumento de planejamento utilizado por todas as Visas municipais é o plano de ações anual.

Os coordenadores relataram que a partir do planejamento é possível nortear as atividades da Visa a ser realizadas, priorizando trabalhos em áreas mais frágeis do órgão e buscando a melhor logística nas ações externas. Porém, observou-se que alguns vícios gerenciais são cometidos, como a repetição do mesmo plano de açōes do ano anterior com pequenas modificações de dados. A falta de interesse em buscar novos métodos de trabalho a ser inseridos no plano anual de ações foi sentida durante os diálogos.

No decorrer dos anos, percebemos que as demandas são praticamente as mesmas, por isso seguimos um mesmo modelo de trabalho faz algum tempo... (E11).

Maragon et al. (2010) afirmam, em seu estudo, que para a elaboração de um plano de ações coeso com a realidade local é necessário que previamente sejam determinadas diretrizes norteadoras que sigam o conceito ampliado de saúde. Nesse processo, é imprescindível que haja uma melhor articulação com a sociedade, através de uma gestão mais participativa, que surgirá como ferramenta de suporte e reestruturação dos serviços da Visa.

De acordo com os depoimentos, a descentralização dos sistemas de informações ligados à Visa melhorou a logística de trabalho, porém, é sentido um aumento na demanda de tarefas a ser realizadas pelo órgão municipal, já que antes a alimentação dos sistemas ficava sob a responsabilidade da regional de saúde, como relatou o entrevistado:

[...] Nós colhíamos os dados e enviávamos para o pessoal da regional de saúde conferir e alimentar os sistemas (E1).

Em alguns municípios, o órgão municipal de Visa ainda não realiza o cadastro de estabelecimentos ou não os atualiza periodicamente, o que faz com que não tenham a informação sobre a quantidade correta de estabelecimentos no município que precisam ser fiscalizados pela Visa. Problemas com proprietários que não disponibilizam documentos para o cadastro e recadastramentos anuais foram relatados na maioria das falas, como também a falta de técnicos jurídicos nos órgãos para o embasamento de decisões a ser tomadas pelas equipes. Percebese a inexistência de um código sanitário, o que coaduna com as dificuldades jurídicas sentidas rotineiramente pelos órgãos municipais. 
O município possui um código sanitário vigente, porém ele deixa muito a desejar

em quase todos os âmbitos, então nós utilizamos mais o estadual, por estar mais completo (E3).

Em outros casos, o código sanitário está em processo de construção ou aguardando os trâmites legais para aprovação no Legislativo e sanção do Executivo. A elaboração de um código sanitário passa por um processo intenso de mobilização e discussão para a proposição de normas sanitárias. Os profissionais atuantes nos órgãos de Visa devem adquirir a consciência de que eles também fazem parte do grupo de atores que trabalham na construção desse instrumento, que deve estar em consonância com a realidade local.

\section{Consideraçôes finais}

Os serviços de Vigilância Sanitária nos municípios estudados ainda apresentam fragilidades no que se refere ao processo de descentralização de ações e na sua estrutura organizacional, não conseguindo responsabilizarem-se em sua totalidade pelas demandas em seu território, com reflexos no processo de trabalho desenvolvido pelos profissionais junto a esse órgão. A diretriz de descentralização no âmbito da Visa municipal torna-se primordial para maior eficiência e resolutividade, exigindo-se, portanto, maior engajamento entre gestores e as equipes envolvidas, considerando-se os preceitos básicos e as políticas que norteiam a vigilância em saúde em nível nacional.

Como limitações do estudo, aponta-se o fato de a avaliação concentrar-se apenas na visão de coordenadores e ter uma abrangência local, embora se considere que as informações produzidas se assemelham a outras realidades e contribuem para o processo de planejamento da rede de atenção à saúde. Reconhece-se a necessidade de ampliação do debate em torno da qualidade dos serviços prestados pela Visa entre os municípios brasileiros, mediante a realização de novos estudos nesse campo, além de maiores investimentos nas políticas de qualificação e de educação permanentes voltadas aos coordenadores e profissionais atuantes. Reforça-se o estímulo na busca pela gestão democrática e interdisciplinar na Visa para garantir maior autonomia aos municípios, para que possam desenvolver seus processos operacionais e potencializar o diálogo intersetorial envolvendo a tríade gestão, serviços e sociedade. ${ }^{1}$ 


\section{Referências}

BRASIL. Lei n. 8.080, de 19 de setembro de 1990. Dispõe sobre as condições para a promoção, proteção e recuperação da saúde, a organização e o funcionamento dos serviços correspondentes. Brasília: Diário Oficial da União, 20 set. 1990.

COHEN, M.M. Dilemas do processo de gestão descentralizada da vigilância sanitária no Estado do Rio de Janeiro. Physis: Rev. Saúde Colet. Rio de Janeiro, v. 19, n. 3, p. 867-901, 2009. COSTA, E.A. (Org.). Vigilância Sanitária: temas para debate [on-line]. Salvador: EDUFBA, 2009. 237p. ISBN 978-85-232-0652-9. Available from SciELO Books <http://books.scielo.org>. COSTA, E.A.; FERNANDES, T.M.; PIMENTA, T.S. A vigilância sanitária nas políticas de saúde no Brasil e a construção da identidade de seus trabalhadores (1976-1999). Ciência \& Saúde Colet. Rio de Janeiro, v. 13, n. 3, p. 995-1004, 2008.

FERRARO, A.H.A.; COSTA, E.A.; VIEIRA-DA-SILVA, L.M. Imagem-objetivo para a descentralização da vigilância sanitária em nível municipal. A framework for health surveillance decentralization. Cad. Saúde Pública, v. 25, n. 10, p. 2201-2217, 2009.

GARIBOTTI, V.; HENNINGTON, É.A.; SELLI, L. A contribuição dos trabalhadores na consolidação dos serviços municipais de vigilância sanitária. Workers' contribution to the consolidation of municipal health surveillance services. Cad. Saúde Pública, v. 22, n. 5, p. 1043-1051, 2006.

LEAL, C.O.B.S.; TEIXEIRA, C.F. Análise de situação dos recursos humanos da vigilância sanitária em Salvador-BA, Brasil. Interface: Comunicação, Saúde, Educação. Botucatu, v. 13, n. 30, p. 167-179, 2009.

MARANGON, M.S.; SCATENA, J.H.G.; COSTA, E.A. A descentralização da vigilância sanitária no município de Várzea Grande, MT (1998-2005). Revista de Administração Pública. Rio de Janeiro, v. 43, n. 2, p. 457-479, 2009.

. Vigilância sanitária: estratégias para sua descentralização em Mato Grosso, 19962005. Ciência \& Saúde Colet. Rio de Janeiro, 2010.

MELO, M.A. de S. et al. Comprometimento organizacional de trabalhadores da vigilância sanitária em municípios do estado de Goiás. Trab. Educ. Saúde. Rio de Janeiro, v. 12, n. 3, p. $655-677$, set./dez. 2014

MINAYO, M.C. de S. et al. Pesquisa social: teoria, método e criatividade. Vozes, 2013. 109p. SANTOS, D.T.G.; CANCIANI, P.M.C. A concretização do princípio da igualdade nas questôes de gênero: as mulheres e as relações de trabalho. In: CONGRESSO LATINOAMERICANO DE GÊNERO E RELIGIÃO. Anais... 2016. p. 133-146.

SOUZA, G.S.; COSTA, E.A. Considerações teóricas e conceituais acerca do trabalho em vigilância sanitária, campo específico do trabalho em saúde. Ciência \& Saúde Colet. Rio de Janeiro, v. 15, n. Supl. 3, p. 3329-3340, 2010. 
SOUZA, J.S. de; STEIN, A.T. Vigilância sanitária de uma cidade metropolitana do sul do

Brasil: implantação da gestão plena e efetividade das açôes. Ciência \& Saúde Colet. Rio de Janeiro, v. 13, n. Supl. 2, p. 2225-2238, 2008.

VERSYPLE, N.I. et al. Microrregião Pajeú: economia, clima e desenvolvimento da agricultura através de modelo digital do terreno|Micro region Pajeú: economy, climate and development of agriculture through model digital terrain. Revista Geama, v. 1, n. 1, 2015.

\section{Nota}

${ }^{1}$ E.F. de Medeiros realizou revisão sistemática da literatura, coleta e análise dos dados. M. Machado orientou a pesquisa, realizou revisão sistemática da literatura, análise dos dados e discussão dos resultados. J.M. Pessoa Júnior foi co-orientador da pesquisa e realizou análise dos dados e discussão dos resultados. 


\section{Evaluation of structural organization of municipal health surveillance of Pernambuco Health Region}

This study aimed to evaluate the organizational structure of the health surveillance of 11 municipalities that are included in the 10th health region of Pernambuco State, Brazil. This is a descriptive and qualitative research that had as subjects 11 health coordinators. We used the interview technique based on semi-structured script. Data were obtained through technical "discourse analysis" in which communication has been interpreted as a process respecting the discourse logic. Results indicated fragility of health surveillance municipal services in the actions decentralization process, failing to meet, in their entirety, the demands from the territory. Among the problems, it highlights the lack of human resources; lack of continuing education policy; difficulties in interpersonal relationships between managers; insufficient financial resources; lack of adequate space, own vehicles, technological tools, difficulties in developing intersectoral action and planning management tools. It recognizes the need for greater engagement between managers and workers in the search for restructuring their actions and daily practices, with a view to operating in a decentralized manner, valuing efficiency of its services.

Keywords: health surveillance; decentralization; health management; structure of services. 